\title{
Editorial
}

\section{MITOS SOCIALES Y RIESGOS PSICOSOCIALES}

En el año 2013 se promulgó en Chile el "Protocolo de Vigilancia de Riesgos Psicosociales en el Trabajo”, marco legal y de atribución del Ministerio de Salud, que mide la existencia y magnitud de los factores de riesgo psicosocial en las organizaciones a través del instrumento SUSESO-ISTAS 21, protocolo que busca identificar a los grupos de trabajadores con mayor exposición frente a los riesgos psicosociales, vigilar su incidencia y sus comportamientos asociados, y generar líneas de trabajo abocadas a disminuir su prevalencia y su potencial daño concomitante en las personas.

Esta problemática en cuestión ha sido objeto de un extenso debate público y erudito, planteándose grandes interrogantes sobre el desarrollo de esta directriz legal en virtud de la construcción nacional de la principal línea base determinada por los primeros datos de las organizaciones de los diferentes sectores productivos del país.

Se trata de un aspecto de gran relevancia y de relativo rápido conocimiento que incide cada vez más, con mayor fuerza y premura, en la

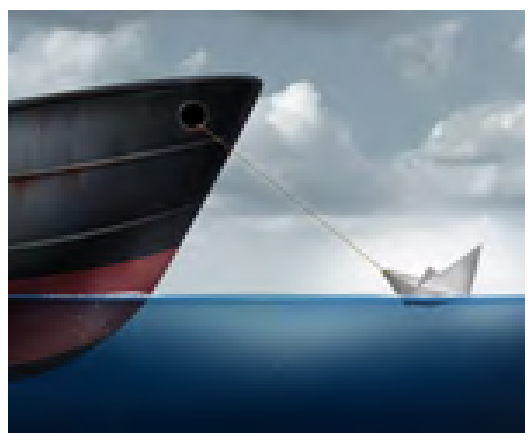

al incluir estas importantes variables en el devenir de las organizaciones; (c) "Tendremos que pedir más recursos", principio falso, que conlleva una gran barrera a la hora de intervenir los factores de riesgo psicosocial de orden laboral, básicamente, ya que el centrarnos en los recursos materiales y económicos, nos desenfoca de la principal responsabilidad que una organización posee en el deterioro de la calidad de vida de las personas, la cual no se asume de modo esencial mejorando por intermedio de más dinero, sino optimizando los entornos psicosociales, enfrentando la condición presente de los procesos de trabajo (turnos, funciones, reconocimientos, promociones, etc.), las relaciones interpersonales, los estilos de liderazgo, la comunicación, los valores, etc., aspectos que muchas veces requieren replanteamientos, lo cual es el alma de la intervención de los riesgos psicosociales; (d) "Debemos circunscribirnos a lo que la ley nos dice”, opinión sesgada, que posesiona la acciones de mitigación de los efectos de los factores de riesgo psicosocial al plano de un proceso recurrente y de limitado desarrollo, importancia de definir las metodologías, los estándares y las particularidades que la intervención debe necesariamente cumplir para eliminar o controlar estos nocivos factores dentro del marco que la evidencia científica define.

En este contexto son variados los mitos sociales existentes que se pueden identificar respecto a la intervención de los factores de riesgo psicosocial en el trabajo. Mitos que se configuran como poderosas barreras frente a las acciones tendientes a generar espacios laborales más sanos y seguros para las personas, dentro de los cuales destacan: (a) "Los Riesgos Psicosociales es un tema imposible de hacernos cargo...”, aseveración carente de fundamento teórico y aplicado, ya que la evidencia científica demarca variada experiencia donde el desarrollo de programas de intervención ha eliminado o controlado los factores de índole psicosocial que han intervenido en el deterioro de las condiciones de salud y seguridad de las personas en diversas contextos laborales y culturales; (b) "Preocuparnos de los Riesgos Psicosociales es más trabajo”, afirmación que no considera la naturaleza de los fenómenos a intervenir, cuestiones tan insertas en el devenir de las prácticas de RRHH, que, seguramente, ya están contempladas en las acciones cotidianas de los procesos y subsistemas de desarrollo de las organizaciones. La cuestión no es complejizar más los procesos laborales de las personas, sino mejorar y optimizar lo que ya se encuentra funcionando, agregándole valor circunstancia carente del sentido de la ley, la cual determina sólo el piso básico donde la organización debería construir y fomentar, cada vez con mayor interés, sus instancias de mejora. De esta manera debería realizarse lo que la ley establece y algo más...; (e) "Los Riesgos Psicosociales generarán ruido en los trabajadores”, aspecto carente de lo que la realidad nos muestra, la cual determina un gran apoyo y compromiso de los sindicatos, comités paritarios y trabajadores en su conjunto. En este sentido las intervenciones de orden participativo, determinan mejores resultados; (f) "Los directivos no considerarán los Riesgos Psicosociales como un aspecto importante, ya que ello no sirve para justificar la gestión", prejuicio que no contempla las exitosas experiencias en el mundo del trabajo. La intervención de riesgos psicosociales en las organizaciones se ciñe bajo los mismos principios de gestión de cualquier otro importante aspecto laboral, principios como la implicación de la dirección, enfoque global, participación, gestión eficaz y coordinación de actividades son de fundamental base, lo cual, a su vez, determina los indicadores de resultados [resultados preventivos (salud de los trabajadores, prevalencia de la exposición y precepción de clima preventivo) / Socio-económicos (eficiencia, cumplimiento normativo e imagen social)]. Cabe señalar que toda intervención debe sustentarse, de manera esencial, en la cúpula de la organización, donde la filosofía determina los principios que condicionan las prácticas de las personas. 